\title{
抄紙機の水分制御の一方式
}

山武ハネウエル株式会社 森亮一

\section{New Moisture Control Method for Paper Machine}

Ryoichi Mori

Yamatake-Honeywell Co., Ltd.

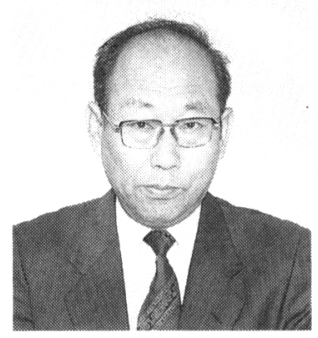

Presented in this paper is a novel method to improve machine-direction moisture profile in paper machine.

Kalman Filter is employed to compensate the time-varying dead time in moisture control loop. Effect of moisture-basis weight interaction is deliberately utilized in building the control scheme. Stability analysis is tried out in Laplace plane in classical manner.

\section{1. まえがき}

製紙工程の中でも，抄紙機は鉄龬の圧延プロセスに 似て高速で, しかも, 制御量の種類が多く, 制御の対 象としては難しいものの一つである。1970 年前後から, セルフ・チューニング・レギュレータなど新しい制御 手法が適用され，制御性の改善例は増加している。問 題は短い周期での多変数制御を実現寸る高パフォーマ ンス処理であり，未だ部分的なオフライン処理が必要 なものが多い。ここでは, 未だ課題の多い抄紙機の水 分プロファイル制御向けの簡易化したアルゴリズムの 一つを紹介する。

\section{2.プロセスの特徴}

一般的な抄紙プロセ又を要約すれば，まず，又トッ クと呼ばれる濃度 $0.1 \%$ 程度のパルプの繫濁液をへッ ドボクスで加庄して，スライスと称する数 $\mathrm{mm}$ の間 隔のスリットから高速で射出する。射出されたストッ クは射出速度と一定の関係をもつライン速度で走行军 るワイアで運ばれている間に，水分の大部分を除かれ，
シート状の繊維分が残る。そのシートを何段かのロー ラで加压, 脱水して様々な表面処理をして卷き取る。 この間, プロセス変数として単位面積当りの重量 (Basis Weight), 水分, 灰分, 厚さ, 自色度などは 図 1 に示すように各工程間で，スキャニング型のセン サで測定し，そのうちのいくつかは制御のために使わ れる。流れに直角の方向（幅方向）の主要な制御量は スライスの開度の分布によって支配され，しかも一つ のスライス操作端の動作は隣接するいくつかの操作端 の制御ループと相㕕、涉をもたらす。また, スキャ二 ング型センサの走行速度は, シート線速度に対し, 十 分速いとは言えず，測定機構にむだ時間を含んだ形と なる。また, 走行中のシート上のある点のある時間の Basis Weight (BW) や水分の変動は位置と時間の 関数としての成立のほかに，いずれにも無関係なラン 多成分が加わっていることが知られている。

\section{3. 水分制御系}

抄紙機の水分制御は操作端がプロセスの終端に近い ところにあるにもかかわらず，除湿の時定数が大きく， 


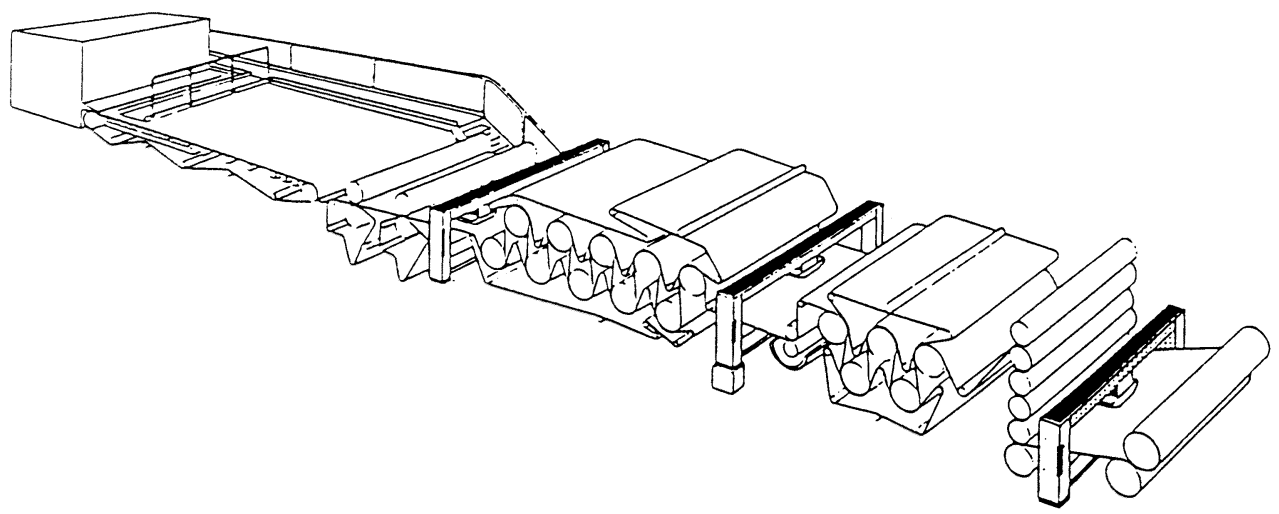

図 1 抄紙機プロセス

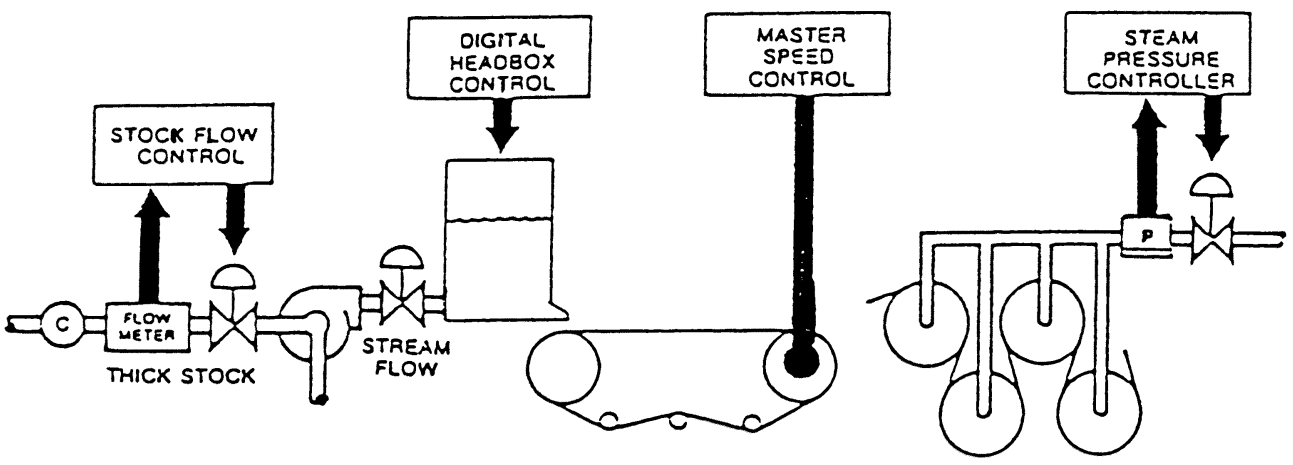

図 2 水分制御系

かつむだ時䦌が底いため，十分な制御性が得られない。 これに刘し，BWの制御系は操作部が最も上流のへ ッドボクス仃りにあるが, プロセスの時定数が小さく， ストックがワイアにに射惴された瞬間にそのプロファ イルが沈䇥される。

水分のブロファイルはスキャニング・センサの中の 少外線吸収センサで検出され，各スキャニングの終わ りに行フロファイルの均值を求め, それを入力して ドライヤの登涂に老制御する。プロセスは一般に

$$
P(S)=\frac{\mathrm{e}^{-1 . S}}{\mathrm{TS}+1}
$$

の形の一次おくれとむだ時間で表現されるので，制御 の炎笠性を維持するため，フィードフォーワード系を 付加したり，図3のようなO。. J Smithのむだ時間 補償ルーフをを加えたりしている。

たな゙，他のブロセスでもへえることであるが，むだ 時閏 Lは常に一䇾上は限らず，様々な要因によって 変動するので, ロ一カル・フォードバック・ループ中 の L も適忍的に変化させなければならない。

ドライヤによる除洎のブロセスは，まずファイバを

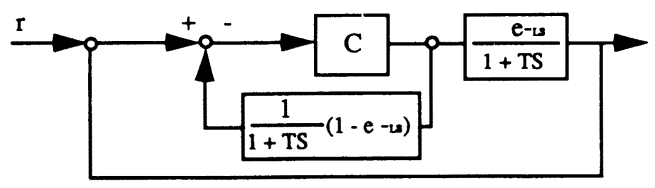

図 3 むだ時間補償ループ

含むシート全体が加熱され，内部がある温度以上にな つた時点で水分の気化が始まり除湿が進むと考えられ る。この気化が始まるまでの加熱時間がむだ時間 $\mathrm{L}$ であり，二つの長さは熱容量に依存するが, ファイバ の重量含有率にシート容積を掛けなファイバ重量流量 が熱容量を代表するとしても決定的な違いはないと考 えられるので,

$$
\mathrm{L}=\mathrm{L}_{\mathrm{O}}+\mathrm{KW}_{\mathrm{F}}(\mathrm{t})
$$

$\mathrm{W}_{\mathrm{F}}(\mathrm{t}):$ ファイバ重量流量

$$
\begin{array}{ll}
\mathrm{K} & \text { : 定数 }>0 \\
\mathrm{~L}_{\mathrm{O}} & \text { : ドライヤ以外のむだ時間 }
\end{array}
$$

という形の補償ができれば，安定領域が拡大寸る。た

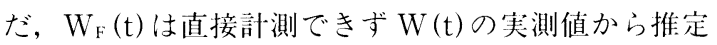
するが, 水分 $\mathrm{M}(\mathrm{t})$ と同じ時点で得られた $\mathrm{W}(\mathrm{t})$ を使 
つたのでは補償の意味がない。そこで， BW の制御 系から, $\mathrm{W}_{\mathrm{F}}(\mathrm{t})$ の未来の最適推定值を $\mathrm{W}_{\mathrm{F}}{ }^{*}(\mathrm{t}+1)$ を 求めて, 補償值とする。今, 単位面積当りのファイバ 重量流量をファイバ濃度 $\mathrm{K}(\mathrm{t})$ とストック流量 $\mathrm{g}(\mathrm{t})$ に より

$$
\mathrm{W}_{\mathrm{F}}(\mathrm{t})=\mathrm{k}(\mathrm{t}) \mathrm{g}(\mathrm{t})
$$

と表し, 動的に

$$
\mathrm{W}_{\mathrm{F}}(\mathrm{t}+1)=\mathrm{aW}_{\mathrm{F}}(\mathrm{t})+\mathrm{W}(\mathrm{t})
$$

と表されるものとする。実際には $\mathrm{W}(\mathrm{t})$ は $\mathrm{K}(\mathrm{t})$ ， ス ライス開度 $\mathrm{U}(\mathrm{t})$ ，へッドボクスのトータル・ヘッド $\mathrm{h}(\mathrm{t})$ の関数であるが, 正規化して平均值 0 , 分散 $\sigma \mathrm{F}$ のガウス分布とし，非がウス成分は次の観測式で吸収 するものとする。観測可能なプロセス変数は BW で あるが，これは水分の項を含んだ形で，

$$
\begin{aligned}
& \mathrm{W}(\mathrm{t})=\mathrm{k}(\mathrm{t}) \mathrm{g}(\mathrm{t})+\beta(\mathrm{t}) \mathrm{g}(\mathrm{t})\{1-\mathrm{k}(\mathrm{t})\} \\
& \beta(\mathrm{t}): \text { 除水率 } 0<\beta(\mathrm{t})<1
\end{aligned}
$$

で表されるので観測方程式は,

$$
\mathrm{W}(\mathrm{t})=(1-\beta) \mathrm{W}_{\mathrm{F}}(\mathrm{t})+\beta(\mathrm{t}) \mathrm{g}(\mathrm{t})+\mathrm{v}(\mathrm{t})
$$

右辺第 2 項と非ガウマ・ノイズ成分 $\mathrm{V}(\mathrm{t})$ を併せて $v^{1}(t)$ と

$$
\begin{aligned}
& \mathrm{v}^{1}(\mathrm{t})=\{1-\lambda(\mathrm{t})\} \mathrm{x}(\mathrm{t})+\lambda(\mathrm{t}) \mathrm{y}(\mathrm{t}) \\
& \text { ただし, } \lambda(\mathrm{t}) \text { は, } \\
& \text { Prob }\{\lambda(\mathrm{t})=1\}=\varepsilon, \text { Prob }\{\lambda(\mathrm{t})=0\}=1-\varepsilon
\end{aligned}
$$

$\mathrm{x}(\mathrm{t}), \mathrm{y}(\mathrm{t})$ は互いに独立な白色ノイズ・プロセスと する。すなわち，へッドボクス回りの制御系に固有の 変動特性が確率を出現すると想定したものである。

$$
\mathrm{E}\left\{\mathrm{v}^{2}(\mathrm{t})\right\}=(1-\varepsilon) \sigma \mathrm{x}^{2}+\varepsilon \mathrm{y}^{2}
$$

状態方程式(4)と観測方程式(6)で表されるカラーシステ ムに対し，Kalmanフィルタは

$$
\begin{aligned}
& \mathrm{W}_{\mathrm{F}}^{*}(\mathrm{t}+1)=\mathrm{aW}_{\mathrm{F}}^{*}(\mathrm{t})+\mathrm{K}(\mathrm{t})\{\mathrm{W}(\mathrm{t})-(1-\beta) \\
& \left.\mathrm{aW} \mathrm{F}^{*}(\mathrm{t})\right\} \\
& \mathrm{K}(\mathrm{t})=\frac{\mathrm{a}(1-\beta) \mathrm{P}(\mathrm{t})}{(1-\varepsilon) \sigma \mathrm{x}^{2}+\varepsilon \sigma \mathrm{y}^{2}+\mathrm{P}(\mathrm{t})(1-\beta)_{2}} \cdots \cdot(11) \\
& \mathrm{P}(\mathrm{t}+1)=\mathrm{a}^{2} \mathrm{P}(\mathrm{t})+\sigma \mathrm{F}^{2}-\mathrm{K}(\mathrm{t}) \mathrm{a}(1-\beta) \mathrm{P}(\mathrm{t})
\end{aligned}
$$

ただし， $\mathrm{P}(\mathrm{t})$ は，予測䛊差 $\mathrm{W}(\mathrm{t})-(1-\beta) \mathrm{aWF}^{*}(\mathrm{t})$ の共分散である。(10)で得られた $\mathrm{WF}^{*}(\mathrm{t}+1)$ を(2)式に 代入して補償要素を更新する。

\section{4.むだ時間補償の近似方式の安定性}

図 3 のむだ時間補償系はローカル・ループに $\mathrm{e}^{-\mathrm{LS}}$ の項目があり，これを簡易なコントーラで実際するの は難しいため,

$$
\frac{1}{1+\mathrm{TS}}\left(1-\mathrm{e}^{-\mathrm{LS}}\right) \fallingdotseq \frac{1}{1+\mathrm{TS}}\left(1-\frac{1}{1+\mathrm{T}_{1} \mathrm{~S}}\right)
$$

で，近似した場合，安定領域がどれだけ狭くなるかが 気になるので，それを呤味する。近似系の一巡伝達関 数は,

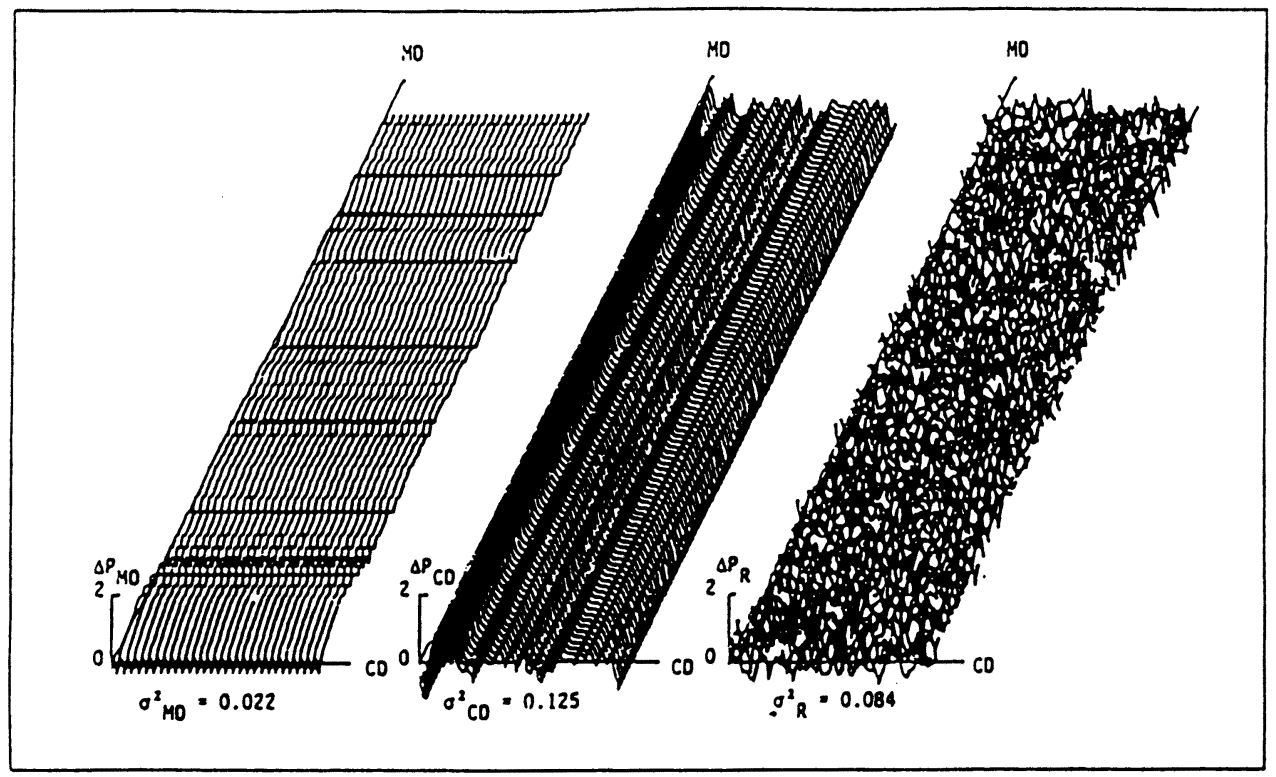

図 4 


$$
\begin{aligned}
G_{0}(S)=\frac{C \frac{1}{1+T S} e^{-1 . S}}{1+\frac{C T_{1} S}{(1+T S)\left(1+T_{1} S\right)}} \\
=\frac{C(1+T S)\left(1+T_{P} S\right) e^{-L S}}{\left\{(1+\mathrm{TS})\left(1+\mathrm{T}_{1} \mathrm{~S}\right)+\mathrm{CT}_{1} \mathrm{~S}\right\}(1+\mathrm{TS})}
\end{aligned}
$$

閉四路の特性: 程式 $1+\mathrm{Go}(\mathrm{S})=0$ は,

$$
\mathrm{C}\left(1+\mathrm{T}_{1} \mathrm{~S}\right) \mathrm{e}^{-1 . \mathrm{S}}+(1+\mathrm{TS})\left(1+\mathrm{T}_{1} \mathrm{~S}\right)+\mathrm{CT}_{1} \mathrm{~S}=0
$$

$$
\mathrm{S} \neq \frac{1}{\mathrm{~T}_{1}} \text { として }
$$

$$
\mathrm{e}^{-\mathrm{LS}}+1+\frac{1}{\mathrm{C}}+\frac{\mathrm{T}}{\mathrm{C}} \mathrm{S}-\frac{1}{1+\mathrm{T}_{1} \mathrm{~S}}=0
$$

コーシーの定理をそのまま応肘すれば，Sが図 5 の ような軌跡を幽くとき，(16)式の左辺（これを $\mathrm{G}(\mathrm{S})$ と

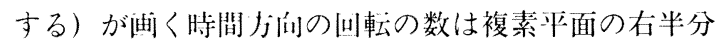
にあるゼロと做の数の差であるが, $\mathrm{G}(\mathrm{S})$ は右半面に 極を持なないから，叮転の数はゼロの数を与え，完全 に $\mathrm{G}(\mathrm{S})$ の軌跡が一问転しなければ，系は安定である。 $\mathrm{G}(\mathrm{S})$ を二つの部分に分け,

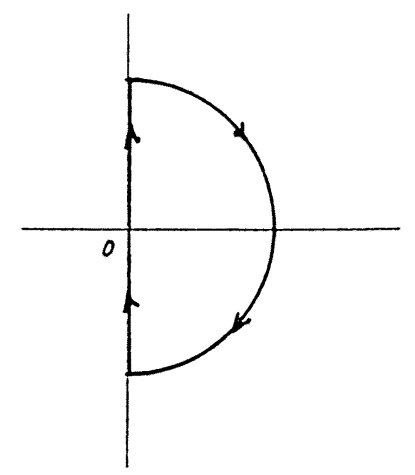

図 5

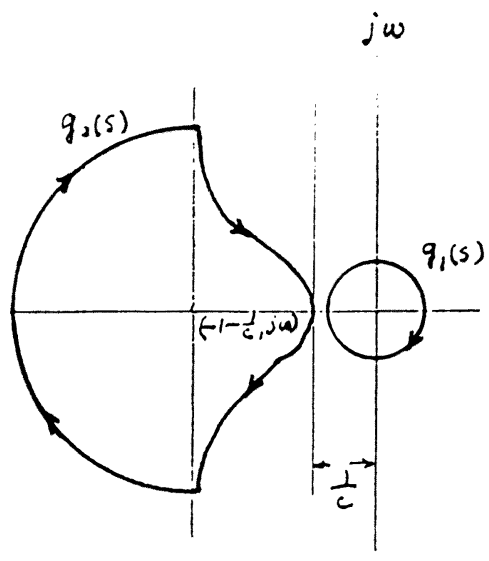

図 6

$$
\begin{aligned}
& \mathrm{G}(\mathrm{S})=\mathrm{g}_{1}(\mathrm{~s})-\mathrm{g}_{2}(\mathrm{~s}) \\
& \mathrm{g}_{1}(\mathrm{~s})=\mathrm{e}^{-\mathrm{LS}} \\
& \mathrm{g}_{2}(\mathrm{~s})=-1-\frac{1}{\mathrm{C}}-\frac{\mathrm{T}}{\mathrm{C}} \mathrm{S}+\frac{1}{1+\mathrm{T}_{1} \mathrm{~S}}=0
\end{aligned}
$$

とすれば，G(S) は始点を $\mathrm{g}_{1}(\mathrm{~s})$ 上に終点を $\mathrm{g}_{2}(\mathrm{~s})$ 上に 有する軌跡を画く。 $\mathrm{g}_{1}(\mathrm{~s})$ は単位山上を時間方向に動き， $\mathrm{g}_{2}(\mathrm{~S})$ は大略, 図6の大のような軌跡を画く。いかな る $\mathrm{L}$ に対しても，G(s)が一回転しないためには $\mathrm{g}_{2}(\mathrm{~s})$ は $\mathrm{g}_{1}(\mathrm{~s})$ の外側にあればよいから，

$$
-\frac{1}{\mathrm{C}}<-\frac{1}{2} \quad \therefore \mathrm{C}<2
$$

すなわち調節器のゲインが 2 以下であれば無条件に系 は安定である。Cを大きくる場合は系は条件的に㚣 定となる。図7において $\mathrm{g}_{1}(\mathrm{~s})$ 上で $\mathrm{g}_{2}(\mathrm{~s})$ より有側す なわち円弧 $\mathrm{PQ}$ の範囲で系は安定である。PQはむだ 時間 Lに比例するのである程度以上 L が大きくなる と不㚣定となる。更に C > > 1 では S 小範囲す なわち低周波域で $\mathrm{g}_{2}(\mathrm{~s})$ は図 8 のように虚軸を接する 川に近くなるので，Q点の横座標は $\mathrm{S}=\mathrm{jw}$ として(17) 式を連立させ，虚部と実部を対照して，

$\mathrm{COS} \omega \mathrm{L}=-\mathrm{T}_{1}{ }^{2} \omega^{2}, \quad \sin \omega \mathrm{L}=\mathrm{T}_{1} \omega$ (19)

より $\mathrm{W}$ を求めて決まるので, 安定条件は,

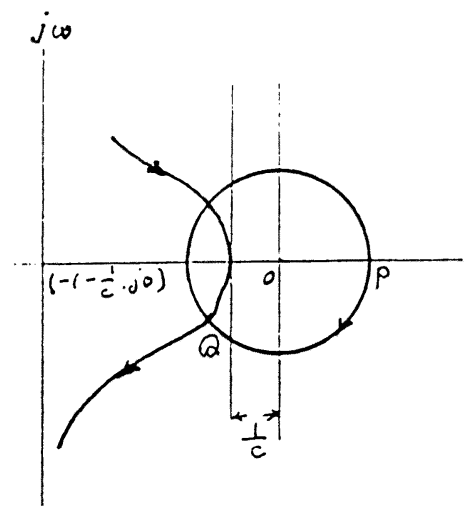

図 7

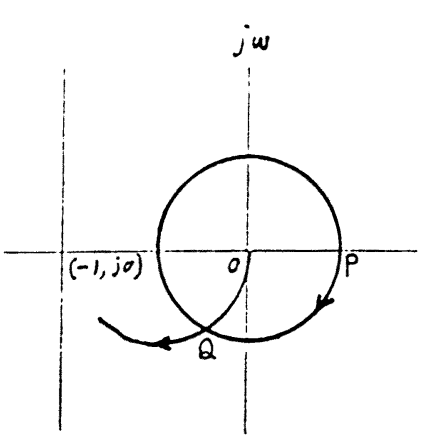

図 8 
124

$$
\operatorname{COS} \frac{\mathrm{L}}{\mathrm{T}_{1}} \frac{\sqrt{\sqrt{5}-1}}{2}>\frac{1-\sqrt{5}}{2}
$$

であり，むだ時間に関する文定条件は， $\mathrm{L}^{*}>\mathrm{L}$ ただし，
森

$\cdots \cdot(20)$
空

$$
\mathrm{L}^{*}=\frac{\sqrt{2}}{\sqrt{\sqrt{5}-1}} \mathrm{~T}_{1}\left(\pi-\operatorname{COS}^{-1} \frac{\sqrt{5}-1}{2}\right)
$$

すなわち，制御対象のむだ時間 $\mathrm{L} は \mathrm{~T}_{1}$ を人きくとれ ば发定を損なわず補償される。 